\title{
Prevalence of Nasal Carriage of Methicillin Resistant Staphylococcus aureus among Health Care Workers in a Tertiary Care Teaching Hospital in Maharashtra, India
}

\author{
Jaishree M. Petkar ${ }^{1}$ and Charan Kaur Dardi ${ }^{2 *}$ \\ ${ }^{1}$ Department of Microbiology, Institution: Government Medical College, Aurangabad, \\ Pin-431001 (Maharashtra State), India \\ ${ }^{2}$ Department of Microbiology, MIMER Medical College, Talegaon, Pune, Pin-410507 \\ (Maharashtra State), India \\ *Corresponding author
}

\begin{abstract}
A B S T R A C T
\section{Keywords}

Healthcare workers, Methicillin-resistant Staphylococcus aureus, MRSA carriage, Nasal carriage,

Staphylococcus aureus

Article Info

Accepted:

12 May 2019

Available Online:

10 June 2019

Methicillin-resistant Staphylococcus aureus (MRSA) is an important cause of hospitalacquired infections in many countries. Mainly healthcare workers (HCWs) are at risk for Methicillin-resistant Staphylococcus aureus carriage. A total of 100 healthcare workers (HCWs) were screened for carriage of MRSA. Nasal swabs collected from both anterior nares were transported to microbiology laboratory and inoculated on Mannitol salt agar plates. The plates were then incubated aerobically at $37^{\circ} \mathrm{C}$ for 24 hours and S. aureus was identified. The standard strains of $S$. aureus were screened for methicillin susceptibility by modified Kirby Bauer method by using cefoxitin discs (30 $\mu$ g) on Muller Hinton agar by using an inoculum density which was equivalent to Mcfarland's 0.5 standard. Isolates which showed inhibition zone sizes of diameter $\leq 21 \mathrm{~mm}$ were identified as MRSA strains. MRSA ATCC 29213 and MSSA ATCC 33591 were used as control for antibiotic susceptibility tests. Overall carriage rate was $15 \%$, with the highest rate in nursing staff $(40 \%)$ while the lowest in Doctors $(26.66 \%)$. Female gender was affected more with $66.66 \%$. Health care workers can be a major source of MRSA in our hospital. There is a need for MRSA control policies in hospitals.
\end{abstract}

\section{Introduction}

Staphylococcus aureus is a human bacterial pathogen which leads to many infections, causing spread from patient to patient in hospital setups and other institutions. However, healthy individuals carry less risk of contracting invasive infections by this organism but can be carriers of this pathogen
(Foster, 2004). Staphylococcal infections cause significant morbidity and mortality in community as well as hospital settings. Treating infections caused by $S$. aureus has become difficult since the development of MRSA (Kumar et al., 2011). In last two decades MRSA has become endemic worldwide (Fadeyi et al., 2010). MRSA has emerged as one of the commonest cause of 
hospital acquired infection since its isolation and it continues to remain as a significant factor contributing to treatment failure (Shakya et al., 2010). MRSA is capable of causing serious manifestations like localized skin and wound infections and may also lead to life threatening infections. Potential reservoirs for MRSA are infected inpatients, hospital personnel and inanimate hospital environment. It can easily spread from one patient to another (Bala et al., 2010).

The main mode of MRSA transmission is from MRSA-colonized or infected patients to another by direct contact, through health care workers (Nour de San et al., 2007). Thus, patients may acquire MRSA from colonized HCWs (Hetty E.M. Blok et al., 2003). Similarly, healthcare providers are also exposed to patients with MRSA infection or are colonized in the course of their work (Akoua Koffi et al., 2004). Nasal carriage is a major risk factor for Staphylococcus aureus infection, especially for MRSA (Methicillin resistant Staphylococcus aureus. Wikipedia, the free encyclopedia, www.wikipedia.com). Anterior nares are the major reservoir of $S$. aureus. $20 \%$ of humans are persistent carriers, $60 \%$ are intermittent and $20 \%$ are noncarriers (González-Zorn et al., 2005).

Screening and eradication of MRSA from colonized healthcare workers have been recognized and recommended as an important part of a comprehensive infection control policy for MRSA (Fadeyi et al., 2010). It was with this background that this study was undertaken in our hospital mainly to screen health care workers for MRSA carriage.

\section{Materials and Methods}

This present prospective cross-sectional study was conducted at Department of Microbiology in a tertiary health care centre. A total of 100 subjects (31 doctors, 33 nursing staff and 36 ward attendants) were screened for MRSA after obtaining informed consent and approval by the institute ethical committee. Complete information about the participants was obtained in a proforma designed for this purpose, after getting their consent. Nasal swabs were collected from both anterior nares with sterile cotton swabs previously moistened with 2 to 3 drops of sterile normal saline. The samples were transported to microbiology laboratory and were processed within 2 hours.

These swabs were inoculated on Mannitol salt agar plates. The plates were then incubated aerobically at $37^{\circ} \mathrm{C}$ for 24 hours and examined for growth. Growth was identified as $S$. aureus by using standard procedures to study colony morphology, microscopic appearance on gram stained smears, catalase test, slide and tube coagulase test (Cheesbrough, 2009).

The standard strains of $S$. aureus were screened for methicillin susceptibility by modified Kirby Bauer method by using cefoxitin discs $(30 \mu \mathrm{g})$ on Muller Hinton agar by using an inoculum density which was equivalent to Mcfarland's 0.5 standard. Isolates which showed inhibition zone sizes of diameter $\leq 21 \mathrm{~mm}$ were considered as MRSA strains (CLSI 2019). MRSA ATCC 29213 and MSSA ATCC 33591 were used as control for antibiotic susceptibility tests. The health care workers who were found to be colonized with MRSA were advised to apply $2 \%$ Mupirocin ointment three times a day in their nares for 5 days. (Apurba S. Sastry and Deepashree, 2019).

\section{Results and Discussion}

A total of 100 healthcare workers, of different age groups and designations were screened for MRSA. Among them 35 were males and 65 were females. Out of which 31 were 
doctors, 33 were nursing staff while Ward attendants i.e. 36 constituted a majority of subjects who were screened. In terms of work experience, maximum HCW i.e. 22 had experience of 1-5 years while the least i.e. 5 HCW had experience ranging from 31 to 40 years (Table 1 and 2).

4 doctors, 6 Nursing staff and 5 Ward attendants were found to be positive for MRSA. Out of which $3 \mathrm{HCWs}$ had work experience of 1-5 years, $5 \mathrm{HCW}$ s had work experience of 6-10 years and 11-15 years each and $1 \mathrm{HCW}$ each were found to be positive for MRSA with work experience ranging from 21-30 years and 31-40 years respectively. Most frequently affected were Nursing staff i.e. 6 in number. Total 10 Female HCW and 5 Male HCW were reported MRSA positive (Table 3 and 4).

Colonization and infection by $S$. aureus are known to be significantly associated with infection among hospitalized patients. (PoLiang Lu et al., 2008).

In our study a total of 100 subjects with work experience range between 1-40 years were screened for MRSA carriage. Among them 35 $(35 \%)$ were males and $65(65 \%)$ were females. From these subjects 31 (31\%) Doctors, 33 (33\%) Nursing staff and 36 (36\%) were Ward attendants. Among 100 health care workers screened, 15 were positive for MRSA at nasal sites, giving a carriage rate of $15 \%$. Among the 35 of males screened $5(14.28 \%)$ were positive, compared to 65 females, $10(15.38 \%)$ of them were positive. The distribution of MRSA carriage across cadre (presented Table 3) was $26.66 \%$ in Doctors, $40 \%$ in nursing staff and $33.33 \%$ in Ward attendants were colonized with MRSA (Table 4).

Table.1 Gender and Designation wise distribution of HCW

\begin{tabular}{|l|l|l|l|}
\hline Parameter & Male & Female & Total \\
\hline Doctors & 14 & 17 & 31 \\
\hline Nursing staff & 03 & 30 & 33 \\
\hline Ward attendants & 18 & 18 & 36 \\
\hline Total & $\mathbf{3 5}$ & $\mathbf{6 5}$ & $\mathbf{1 0 0}$ \\
\hline
\end{tabular}

Table.2 Work Experience wise distribution of HCW

\begin{tabular}{|l|l|l|l|}
\hline $\begin{array}{l}\text { Years of } \\
\text { Experience } \\
\text { in years }\end{array}$ & Doctors & $\begin{array}{l}\text { Nursing } \\
\text { staff }\end{array}$ & $\begin{array}{l}\text { Ward } \\
\text { attendants }\end{array}$ \\
\hline $\mathbf{0 - 1}$ & 02 & 03 & 01 \\
\hline $\mathbf{1 - 5}$ & 11 & 10 & 01 \\
\hline $\mathbf{6 - 1 0}$ & 10 & 06 & 04 \\
\hline $\mathbf{1 1 - 1 5}$ & 03 & 06 & 09 \\
\hline $\mathbf{1 6 - 2 0}$ & 01 & 02 & 08 \\
\hline $\mathbf{2 1 - 3 0}$ & 03 & 05 & 10 \\
\hline $\mathbf{3 1 - 4 0}$ & 01 & 01 & 03 \\
\hline Total & $\mathbf{3 1}$ & $\mathbf{3 3}$ & $\mathbf{3 6}$ \\
\hline
\end{tabular}


Table.3 Gender and Designation wise distribution of MRSA positive HCW

\begin{tabular}{|l|l|l|l|}
\hline Parameter & Male & Female & Total (\%) \\
\hline Doctors & 02 & 02 & $04(26.66 \%)$ \\
\hline Nursing staff & 01 & 05 & $06(40 \%)$ \\
\hline $\begin{array}{l}\text { Ward } \\
\text { attendants }\end{array}$ & 02 & 03 & $05(33.33 \%)$ \\
\hline Total & $\mathbf{0 5 ( 3 3 . 3 4 \% )}$ & $\mathbf{1 0}(\mathbf{6 6 . 6 6 \% )}$ & $\mathbf{1 5}(\mathbf{1 0 0 \% )}$ \\
\hline
\end{tabular}

Table.4 Work Experience wise distribution MRSA positive HCW

\begin{tabular}{|l|l|l|l|}
\hline $\begin{array}{l}\text { Years of Experience } \\
\text { in years }\end{array}$ & Doctors & $\begin{array}{l}\text { Nursing } \\
\text { staff }\end{array}$ & $\begin{array}{l}\text { Ward } \\
\text { attendants }\end{array}$ \\
\hline $\mathbf{0 - 1}$ & 00 & 00 & 00 \\
\hline $\mathbf{1 - 5}$ & 02 & 01 & 00 \\
\hline $\mathbf{6 - 1 0}$ & 01 & 03 & 01 \\
\hline $\mathbf{1 1 - 1 5}$ & 01 & 02 & 02 \\
\hline $\mathbf{1 6 - 2 0}$ & 00 & 00 & 00 \\
\hline $\mathbf{2 1 - 3 0}$ & 00 & 00 & 01 \\
\hline $\mathbf{3 1 - 4 0}$ & 00 & 00 & 01 \\
\hline Total & $\mathbf{0 4}$ & $\mathbf{0 6}$ & $\mathbf{0 5}$ \\
\hline
\end{tabular}

The most frequent carriage site for S. aureus is anterior nares of the nose. S. aureus can also colonize other body sites such as skin, perineum, pharynx, vagina, axilla, and gastrointestinal tract of the human beings. (Wertheim HF., et al., 2005) The reported prevalence of nasal carriage of MRSA among HCWs in hospital settings varies between 5.8\% and 17.8\%. (Eveillard et al., 2004; Mulqueen et al., 2007; Cesur et al., 2004). In the present study, this carriage rate was $15 \%$ which is comparable to a study from Karnataka (India) from where the reported rates were 15\%. (Kalyani et al., 2012) However, studies from Nepal and another state of India (Assam) reported a comparatively lower prevalence $(10 \%$ and $11.43 \%$, respectively) (Shakya et al., 2010; Rongpharpi et al., 2013) Also low prevalence of MRSA (2.32\% and 2\%) has been observed in an another study from Nepal and South India, respectively (Shrestha et al., 2009; Vinodhkumaradithyaa et al., 2009) This difference could be because of the variations in the geographic areas, institutions, hospital specialties, and settings within hospital where the studies were conducted. Disparity in carriage rate can be due to difference in the design of the study and methods used for detection of MRSA.

In the present study, higher proportion of MRSA carriage was observed among the nursing staff $(40 \%)$ as compared to doctors and ward attendants. This is similar to the findings of Kalyani et al., (2012).

The mechanism leading to MRSA nasal carriage is multifactorial and not properly understood, but higher carriage rate in nursing staff poses a big epidemiological challenge because nursing staff are the HCWs who have the highest frequency of contact with the patients and could probably be the reservoir of infection, thus responsible for continuance of the infection in the hospital environment. 
Majority of the MRSA carriers of our study were females which is similar to the finding of Vijaya et al., (2011). In contrast, Mathanraj et $a l$., and another review studies reported male sex as an important risk factor for MRSA colonization (Akoua Koffi et al., 2004; Wertheim et al., 2005; Mathanraj et al., 2009) However, the role of gender including that of sex hormones in MRSA carriage is controversial and needs further study.

Health care workers can be a major source of MRSA in our hospital. Active surveillance for MRSA should be carried out for health care workers who are epidemiologically linked to MRSA outbreak or who are working for long time in MRSA prevalent units. There is need for the development, adoption and enforcement of appropriate infection control policies in hospitals for effective MRSA control.

\section{References}

Akoua Koffi C, Dje K, Toure R, Guessennd N, Acho B, Faye Kette H, et al., Nasal carriage of methicillin-resistant Staphylococcus aureus among healthcare personnel in Abidjan (Cote d'Ivorine) Dakar Med. 2004; 49: 70-74.

Apurba S. Sastry, Deepashree R. Essentials of Hospital Infection Control. New delhi. Jaypee Medical Publisher; 2019. p-376.

Bala K, Aggarwal R, Goel N, Chaudhary U. Prevalence and Susceptibility Patterns of Methicillin Resistant Staphylococcus aureus (MRSA) Colonization in a Teaching Tertiary Care Center in India. J Infect Dis Antimicrob Agents. 2010; 27(1): 33-8.

Cesur S, Cokça F. Nasal carriage of methicillin-resistant Staphylococcus aureus among hospital staff and outpatients. Infect Control Hosp Epidemiol. 2004; 25: 169-71.
Cheesbrough M. District Laboratory practice in Tropical countries. Part 2. Cambridge. Cambridge University Press; 2009; 62-68

CLSI. M100 Performance standards for Antimicrobial Susceptibility Testing. Wayne PA. $29^{\text {th }}$ edition; 2019.

Eveillard M, Martin Y, Hidri N, Boussougant Y, Joly-Guillou ML. Carriage of methicillin resistant Staphylococcus aureus among hospital employees: Prevalence, duration, and transmission to households. Infect Control Hosp Epidemiol. 2004; 25: 114-20.

Fadeyi A, Bolaji BO, Oyedepo O. Methicillin resistant Staphylococcus aureus, carriage among health care workers of critical care units in a Nigerian hospital. American Journal of Infectious Diseases 2010; 6(1): 18-23.

Foster TJ. The Staphylococcus aureus "superbug". J Clin Invest. 2004; 114: 1693-96.

González-Zorn B, Senna JP, Fiette L, Shorte S, Testard A, Chignard M. et al., Bacterial and Host Factors Implicated in Nasal Carriage of Methicillin-Resistant Staphylococcus aureus in Mice. Infect Immun. 2005 Mar; 73(3): 1847-51.

Hetty EM Blok, Annet Trolestra, Titia EM Kamp-Hopmans et al., Role of health care workers in outbreaks of Methicillin resistant Staphylococcus aureus: A 10year evaluation from a Dutch University hospital. Infect Control Hosp Epidemiol. 2003 Sep; 24(9): 679-85.

Kalyani K, Jayakumari K, Kumar JS. Prevalence of MRSA among HCWs of Shri Satya Sai Medical College and Hospital - A tertiary care centre. J Dent Med Sci. 2012; 3: 23-7.

Kumar P, Shukla I, Varshney S. Nasal screening of healthcare workers for nasal carriage of coagulase positive MRSA and prevalence of nasal colonization with Staphylococcus 
aureus. Biology and medicine. 2011; 27(1): 62-64.

Mathanraj S, Sujatha S, Sivasangeetha K, Parija SC. Screening for methicillinresistant Staphylococcus aureus carriers among patients and health care workers of a tertiary care hospital in South India. Indian J Med Microbiol. 2009; 27: 624.

Methicillin resistant Staphylococcus aureus. Wikipedia, the free encyclopedia, www.wikipedia.com.

Mulqueen J, Cafferty F, Cormican M, Keane JD, Rossney A. Nasal carriage of MRSA in GPs in the west of Ireland. $\mathrm{Br}$ J Gen Pract. 2007; 57: 811-3.

Nour de San, Olivier Denis Marie-Fabrice Gasarira, Ricardo De Mendonca, et al., Controlled Evaluation of the IDI-MRSA Assay for Detection of Colonization by Methicillin-Resistant Staphylococcus aureus in Diverse Musculocutaneous Specimens. Journal of Clinical Microbiology 2007; 45: 1098-1101.

Po-Liang Lu, Jer-Chia Tsai, Yi-Wen Chiu, Feng-Yee Chang, Ya-Wei Chen, Chin$\mathrm{Fu}$ Hsiao et al., Methicillin-resistant Staphylococcus aureus carriage, infection and transmission in dialysis patients, healthcare workers and their family members, Nephrology Dialysis Transplant. 2008; 23: 1659-1665.

Rongpharpi SR, Hazarika NK, Kalita H. The prevalence of nasal carriage of Staphylococcus aureus among healthcare workers at a tertiary care hospital in Assam with special reference to MRSA. J Clin Diagn Res. 2013; 7: 257-60.

Shakya B, Shrestha S, Mitra T. Nasal carriage rate of methicillin resistant Staphylococcus aureus among at National Medical College teaching hospital, Birgunj, Nepal. Nepal Med Coll J. 2010; 12: 26-9.

Shakya B, Shrestha S, Mitra T. Nasal carriage rate of methicillin resistant Staphylococcus aureus among at National Medical College Teaching Hospital, Birgunj, Nepal. Nepal Med Coll J. 2010 Mar; 12(1): 26-9.

Shrestha B, Pokhrel BM, Mohapatra TM. Staphylococcus aureus nasal carriage among health care workers in a Nepal Hospital. Braz J Infect Dis. 2009; 13: 322.

Vijaya D, Jankiran K, Sathish JV, Santhosh J. Nasal carriage of MRSA in hospital personnel. J Academy of Clin Microbiol. 2011; 13: 71-6.

Vinodhkumaradithyaa A, Uma A, Shirivasan M, Ananthalakshmi I, Nallasivam P, Thirumalaikolundusubramanian P. Nasal carriage of methicillin-resistant Staphylococcus aureus among surgical unit staff. Jpn J Infect Dis. 2009; 62: 228-9.

Wertheim HF, Melles DC, Vos MC, Van Leeuwen W, Van Belkum A, Verbrugh $\mathrm{HA}$, et al., The role of nasal carriage in Staphylococcus aureus infections. Lancet Infect Dis. 2005; 5: 751-62.

\section{How to cite this article:}

Jaishree M. Petkar and Charan Kaur Dardi. 2019. Prevalence of Nasal Carriage of Methicillin Resistant Staphylococcus aureus among Health Care Workers in a Tertiary Care Teaching Hospital in Maharashtra, India. Int.J.Curr.Microbiol.App.Sci. 8(06): 1430-1435. doi: https://doi.org/10.20546/ijcmas.2019.806.173 